\title{
ASSESMENT OF DURATION OF ANALGESIA BY COMPARING INTRATHECAL BUPIVACAINE WITH KETAMINE AND HYPERBARIC BUPIVACAINE FOR CAESAREAN SECTION PATIENTS
}

Amit Jain ${ }^{1}$, Satyendra Uike², Nidhi Mishra ${ }^{3}$, Sarvesh Jain 4 , V. M. Agnihotri ${ }^{5}$

\section{HOW TO CITE THIS ARTICLE:}

Amit Jain, Satyendra Uike, Nidhi Mishra, Sarvesh Jain, V. M. Agnihotri. "Assesment of Duration of Analgesia by Comparing Intrathecal Bupivacaine with Ketamine and Hyperbaric Bupivacaine for Caesarean Section Patients". Journal of Evolution of Medical and Dental Sciences 2014; Vol. 3, Issue 47, September 25; Page: 11429-11435, DOI: $10.14260 /$ jemds/2014/3494

ABSTRACT: OBJECTIVE: Spinal Anesthesia is the most preferred technique of anesthesia for lower segment caesarean section which provides effective pain relief during intraoperative and initial postoperative period. Various intrathecal adjuvant for postoperative pain relief have been tried which provide suboptimal analgesia and various side effects on maternal and fetus. We planned to assess the duration of analgesia by comparing intrathecal hyperbaric bupivacaine with preservative free ketamine and hyperbaric bupivacaine alone in parturient undergoing caesarean section. METHODS: A prospective, randomized, controlled study was conducted on 100 pregnant patients belonging to ASA I \& II scheduled for LSCS under spinal anesthesia. Study comprised of two groups of 50 patients each. The first group received $2 \mathrm{ml}$ of Hyperbaric Bupivacaine $0.5 \%+25 \mathrm{mg}$ Preservative free Ketamine while group II received $2 \mathrm{ml}$ of Hyperbaric Bupivacaine 0.5\%. RESULTS: The mean duration of postoperative analgesia was $160 \pm 0.6$ minutes in group I and $120 \pm 0.7$ minutes in group II, $P$ value $<0.001$. Incidence of hypotension and bradycardia was less in group I as compared to that of group II. Apgar score was statistically insignificant in both the groups. CONCLUSIONS: Addition of 25mg preservative free ketamine to hyperbaric bupivacaine in spinal anesthesia for LSCS significantly prolongs the duration of postoperative analgesia with better intraoperative hemodynamically stability and without any adverse effect on neonates.

KEYWORDS: hyperbaric $0.5 \%$ bupivacaine, preservative free ketamine, intrathecal.

INTRODUCTION: Spinal anaesthesia is the most preferred technique in parturient, undergoing for lower segment caesarean sections (LSCS) and several adjuvants has been tried along with local anaesthetic for prolongation of postoperative analgesia.(1)

Better postoperative analgesia will improve mother child interaction and breastfeeding and infant well-being. Regional anaesthesia for LSCS has distinct advantages over general anaesthesia because of better postoperative analgesia, avoiding the problem of a difficult airway, less risk of aspiration and less neonatal exposure to drugs.

Bupivacaine is being more preferred because of prolong duration of action, more potent and less neurotoxic than lignocaine. Ketamine is a phencyclidine derivative anaesthetic agent which is most commonly used by intravenous access. Intrathecally it has beneficial effects on cardiovascular function, good analgesic and local anaesthetic effect in many studies.(2-4)

We planned to assess the duration of analgesia by comparing intrathecal bupivacaine with ketamine and hyperbaric bupivacaine in parturient undergoing caesarean section. 
METHODS: A prospective, randomized, controlled study was conducted at Bundelkhand Medical College, Sagar. The parturient were randomly allocated to two groups of 50 patients in each group. The spinal anaesthetic agents to be used were:

Group I: $(\mathrm{n}=50)$ received $2 \mathrm{ml}$ of $0.5 \%$ Hyperbaric Bupivacaine (sensorcaine) $+25 \mathrm{mg}$ Preservative free Ketamine (aneket ampoule) was administered injecting hyperbaric bupivacaine first.

Control Group II: $(\mathrm{n}=50)$ received $2 \mathrm{ml}$ of $0.5 \%$.Hyperbaric Bupivacaine.

After approval of the institutional ethics committee and written consent from the patients, 100 parturient, aged 20-24 years belonging to ASA physical status I and II, undergoing elective caesarean section were included in our study.

Females with known allergic to local anaesthetic and ketamine, contraindications to spinal anaesthesia, pregnancy induced hypertension, placenta previa, foetal distress and multiple pregnancies were excluded from the study.

In all patients, injection ranitidine $50 \mathrm{mg} \&$ metoclopramide $10 \mathrm{mg}$ was administered for 30 minutes before the spinal anaesthesia. Preloading was done with $10-15 \mathrm{ml} / \mathrm{kg}$ of Ringer Lactate solution. Under strict aseptic precaution spinal anaesthesia was administered using 25G Quincke spinal needle in L3-4 intervertebral space by midline approach in left lateral position by an anaesthesiologist blind to the drug used.

On completion of the spinal injection the patients were immediately placed in supine position with a wedge under right hip. Supplementation of oxygen $4 \mathrm{~L} / \mathrm{min}$ was given to all patients through a venti mask. Non-invasive arterial blood pressure, heart rate, peripheral oxygen saturation $\left(\mathrm{SPO}_{2}\right)$ \& respiratory rates were monitored every 3 minutes for the first 20 minutes then every 5 minutes till end of surgery.

Following parameter were observed and noted for:

1. Comparison of sensory and motor block in term of onset, duration and intensity.

A. Onset and intensity of sensory block assess by pin prick and duration by regression time of sensation to return to T-12 dermatome.

B. Onset of motor block by modified bromagae scale and duration of motor block by assessment of appearance of great toe movement.

2. Effect on CVS by assessment of heart rate and SBP and DBP.

3. Central effect by level of sedation assessed by 4 point scale.

4. Duration of postoperative analgesia was taken as the time to the first request for a rescue systemic analgesic.

5. Discomfort during fundal pressure and foetal wellbeing by Apgar score.

There was no significant difference between total surgical time and procedure in both the groups. Analysis of data was performed by using student's t-test and chi-square test and p-value less than 0.05 was considered as statistically significant.

OBSERVATION AND RESULT: The demographic profile of two groups in terms of age, weight, height \& gender was similar and comparable. The onset of Sensory block as assessed by loss of sensation with pin prick method ranged between 1 to 2 minutes in the group I with mean \pm (SD) of $1.2 \pm 0.5$ 
while it was 2 to 3.4 minutes with a mean \pm (SD) of $2.4 \pm 0.5$ in group I, difference was statistically significant $(\mathrm{P}<0.01)$.

The onset of motor block determined by loss of movements of lower limbs in group I was 23.4 min with a mean \pm (SD) of 2.35 0.07 (SD) as compared to 3-9.5 minutes with a mean \pm (SD) of $5.97 \pm 0.27$ in group II; difference was statistically significant $(\mathrm{P}<0.01)$.

\begin{tabular}{|l|c|c|c|c|}
\hline In minute & \multicolumn{2}{|c|}{ Onset of sensory block } & \multicolumn{2}{c|}{ Onset of motor block } \\
\hline & Group 1 & Group 2 & Group 2 & Group 2 \\
\hline Range (mins) & $1-2$ & $2-3.4$ & $2-3.4$ & $3-9.5$ \\
\hline Mean & $1.2 \pm 0.5$ & $2.4 \pm 0.5$ & $2.35 \pm 0.07$ & $5.97 \pm 0.27$ \\
\hline
\end{tabular}

TABLE 1:Onset of sensory and motor block

P value: $<0.01$ (significant).

Duration of sensory block was 100-150 minutes with a mean \pm (SD) of $144 \pm 4.4$ minutes in group I while it was 90-120 minutes with a mean \pm (SD) of 100 \pm 5.4 in group II; difference was statistically significant again $(\mathrm{P}<0.01$ )(Table 2). Duration of motor block was 90-140 minutes with a mean \pm (SD) of $122 \pm 1.79$ minutes in group I while it was 90-150 minutes with a mean \pm (SD) of $118 \pm 2.34$ minutes in group II which is not statistically significant (Table 2).

\begin{tabular}{|c|c|c|c|c|}
\hline \multirow{2}{*}{ In minute } & \multicolumn{3}{|c|}{ Duration of sensory block } & Duration of motor block \\
& Group 1 & Group 2 & Group 1 & Group 2 \\
\hline Range(min) & $100-150$ & $90-120$ & $90-140$ & $90-150$ \\
\hline Mean(min) & $144 \pm 4.4$ & $100 \pm 5.4$ & $122 \pm 1.79$ & $118 \pm 2.34$ \\
\hline
\end{tabular}

P value: $<0.01$ (significant).

\begin{tabular}{|l|c|c|}
\hline \multicolumn{1}{|c|}{ GRADE } & Group I & Group II \\
\hline 0 (Normal) & NIL & NIL \\
\hline 1 (Mild) & NIL & NIL \\
\hline 2 (Moderate) & NIL & $4(8 \%)$ \\
\hline 3 (Complete loss of sensation) & $50(100 \%)$ & $46(92 \%)$ \\
\hline \multicolumn{2}{|c|}{ TABLE 3: Intensity of sensory block } \\
\hline \multicolumn{2}{|c|}{}
\end{tabular}

\begin{tabular}{|c|c|c|}
\hline Grade & Group I & Group II \\
\hline+ & NIL & NIL \\
\hline++ & NIL & $3(6 \%)$ \\
\hline+++ & $50(100 \%)$ & $47(94 \%)$ \\
\hline
\end{tabular}

TABLE 4: Gradation of motor paralysis: By Modified Bromage scale 
In group I, all the patients had complete motor and sensory block, whereas in group II, 3 patients had incomplete motor block, but they had a complete sensory block, so LSCS was done comfortably without requiring any further intervention. In Group II, 4 patients had moderate loss of sensation but they had complete motor block and so they were required to be supplemented with $30 \mathrm{mg}$ pentazocine and $5 \mathrm{mg}$ diazepam.

\begin{tabular}{|l|c|c|}
\hline & Group I & Group II \\
\hline 0 (Normal) & $49(98 \%)$ & 50 \\
\hline 1 (Drowsiness) & $1(2 \%)$ & NIL \\
\hline 2 (Sleep but arousable) & NIL & NIL \\
\hline 3 (Unarousable with loss of verbal contact) & NIL & NIL \\
\hline \multicolumn{2}{|c|}{ TABLE 5: Central nervous system effect: level of Sedation } \\
\hline
\end{tabular}

In group I only one patient had drowsiness because of which we did not encounter any problem, while no adverse effect on central nervous system was noticed in group II patients.

\begin{tabular}{|l|c|c|}
\hline & Group I & Group II \\
\hline Not significant & $33(66 \%)$ & $15(30 \%)$ \\
\hline Mild $(11-20 \mathrm{~mm} \mathrm{Hg})$ & $17(34 \%)$ & $20(40 \%)$ \\
\hline Moderate $(21-30 \mathrm{~mm} \mathrm{Hg})$ & NIL & $10(20 \%)$ \\
\hline Severe $(>30 \mathrm{~mm} \mathrm{Hg})$ & NIL & $5(10 \%)$ \\
\hline Mean \pm SD & $10.92 \pm 0.73$ & $16.44 \pm 1.08$ \\
\hline \multicolumn{2}{|c|}{ TABLE 6: Changes in Blood pressure } \\
\hline
\end{tabular}

$P$ value: $<0.001$ (significant)

Change in BP: Mean standard value was taken as 126/76 mm of Hg.

In group II, 20 patients had mild systolic hypotension while 10 patients had moderate and 5 patients had severe systolic hypotension with a mean \pm (SD) of $16.44 \pm 1.08$ while in Group I, 33 patients showed no significant fall in blood pressure \& 17 patients had mild systolic hypotension with a mean $\pm(S D)$ of $10.92 \pm 0.73$ which was statistically significant $(\mathrm{P}<0.01)$.

\begin{tabular}{|l|c|c|}
\hline \multicolumn{3}{|c|}{} \\
\hline & Group I & Group II \\
\hline Not significant & $43(86 \%)$ & $35(70 \%)$ \\
\hline Mild $(11-15)$ & $7(14 \%)$ & $10(20 \%)$ \\
\hline Moderate $(16-20)$ & NIL & $5(10 \%)$ \\
\hline Severe $(21-30)$ & NIL & NIL \\
\hline Mean & $9.0 \pm 0.62$ & $20.92 \pm 1.04$ \\
\hline
\end{tabular}

P value: $<0.001$ (significant)

Standard value was taken as 76 per min (mean). 
In group I, 43 patients had no significant change in pulse rate and 7 patients had mild change in pulse rates. While in Group II, 35 patients had no significant changes in pulse rates while 10 patients had mild change as bradycardia \& 5 had moderate change as bradycardia.

\begin{tabular}{|l|c|c|}
\hline & Group I & Group II \\
\hline Duration & $120-180$ Min & $100-150$ Min \\
\hline Mean & $160 \pm 0.6$ & $120 \pm 0.7$ \\
\hline
\end{tabular}

TABLE 8: Duration of post- operative analgesia

P value: $<0.001$ (significant).

\begin{tabular}{|l|c|c|c|c|}
\hline & Discomfort during fundal pressure & \multicolumn{2}{c|}{ Level of block } \\
\hline & Absent & Present & Up to T6 & Up to T 8 \\
\hline Group 1 & $50(100 \%)$ & NIL & $45(90 \%)$ & $5(5 \%)$ \\
\hline Group 2 & $42(84 \%)$ & $8(16 \%)$ & $35(70 \%)$ & $15(30 \%)$ \\
\hline
\end{tabular}

\begin{tabular}{|l|c|c|}
\hline & \multicolumn{2}{|c|}{ Mean APGAR SCORE range } \\
\hline TIME (minutes) & GROUP 1 & GROUP2 \\
\hline 1 minute & 10 & 10 \\
\hline 5 minute & 10 & 10 \\
\hline \multicolumn{3}{|c|}{ TABLE 10} \\
\hline
\end{tabular}

On comparison, none of the patient in group I, had discomfort with fundal pressure while 8 patients of group II had discomfort which was statistically significant ( $\mathrm{P}<0.01)$. In group I, 45 patients had sensory loss up to T6 dermatome while 5 patients achieved only up to T8 dermatome whereas in group II, 35 patients had sensory loss was up to T6 dermatome while 15 patients achieved up to T8 dermatome.

In both groups, no adverse effect was noted in neonates till 5 minutes.

DISCUSSION: Addition of adjutants to local anaesthesia is preferred as it reduces the severity of postoperative pain and prolongs analgesia which further improves patient comfort.

In 1962, ketamine was synthesized by Dr. Calvin Stevens at the Parke Davis laboratories in Ann Arbor, Michigan.(5) Ketamine, a phencyclidine derivative is an age old anaesthetic agent most commonly used via intravenous access. It was first used intrathecally by BION.(2)

It possesses some definite advantages over the conventional local anaesthetic as it is a potent analgesic and stimulates cardiovascular system and respiratory system. $(3,4,6)$

Ketamine acts on nucleus reticularis gigantocellularis in brain stem (7) and binds with phencyclidine site of $\mathrm{N}$-methyl $\mathrm{D}$-aspartate (NMDA) receptor -gated calcium channel and noncompetitively inhibits the NMDA receptors. ${ }^{(4,8)}$

It also has direct axonal blocking effect and affinity to opiate receptors and monoaminergic receptors, which contributes to the analgesic effect of spinal ketamine. $(4,9-12)$ 
In this study we observed that the onset was rapid and duration of sensory block was prolonged in group I as compare to group II.

The onset of motor block was earlier in group I but the duration of motor block was statistically not significant in both group and observed that better quality of analgesia in intraoperative period is for group I. Singh SP et al (6) and Unlugenc et al,(13) Iida H Dohi S et al(11) also observed in their studies that preservative free ketamine with bupivacaine given intrathecally induced rapid onset of sensory blocked.

In our study incidence of bradycardia and systolic hypotension was observed more in control group II and Hemodynamically patient were more stable in group I as compare to that of group II but in group I, central effect (drowsiness) was observed in one patient.

Similar finding was observed by Kathirvel E et al,(4) Govindan K et al,(14) T. Tiogal et al(15) found in their studies. Duration of analgesia with the group I was longer than group II. Singh SP et al,(6) Bhattacharya D et al,(16) Yang CY et al(17) and Marzieh BK et al(18) also found intrathecal ketamine with bupivacainne enhances the duration of analgesia.

As most of the patient had level of block up to T6 dermatome although patient was comfortable on fundal pressure in group I as compare to that of group II. Apgar score was statistically insignificant in both groups.

CONCLUSION: As per data observed in this study, it could be concluded that intrathecally addition of $25 \mathrm{mg}$ of ketamine with bupivacaine in patients undergoing LSCS results in rapid Onset of sensory and motor block with prolonged duration of sensory block.

The intraoperative hemodynamically stability and the quality of analgesia were better maintained as compared to intrathecal bupivacaine alone. Duration of postoperative analgesia was prolonged by adding ketamine to intrathecal bupivacaine without any significant adverse effect on neonates.

\section{REFERENCES:}

1. Saxena AK, Arava SE. Current concepts in neuraxial administration of opioids and non-opioids: An overview and future perspectives. Indian J Anaesth. 2004; 48:13-24.

2. Bion JF: Intrathecal ketamine for war surgery. Anaesthesia, 1984; 39 (10): 1023-8.

3. Murali Krishna T, Panda NB, Batra YK, Rajeev S. Combination of low doses of intrathecal ketamine and midazolam with bupivacaine improves postoperative analgesia in orthopedic surgery. Eur J Anaesthesiol 2008; 25: 299e306.

4. Kathirvel S, Sadhasivam S, Saxena A, Kanan TR, Ganjoo P. Effects of intrathecal ketamine added to bupivacaine for spinal anaesthesia. Anaesthesia 2000; 55: 899e910.

5. Paul G Barash, Bruce F. Cullen, Robert k Stoelting. Clinical anaesthesia: The history of anesthesia; $6^{\text {th }}$ edt, Lippincott Williams \&Wilkins 2009;p.15

6. Singh SP, Sinha AK, Jha AK. Evaluation of intrathecal ketamine for intraoperative and postoperative analgesia. Indian Journal of Anaesthesia. 1997; 41 (4): 15-8.

7. Ren K, Williams GM, Hylden JLK, Ruda MA, Dubner R. The intrathecal administration of excitatory amino acid receptor antagonists selectively attenuated carrageenan-induced behavioral hyperalgesia in rats. Eur J Pharmacol, 1992; 219: 235e43.

8. Irifune M, Shimizu T, Nomoto M, Fukuda, T. Ketamine induced anesthesia involves the N-methyl-

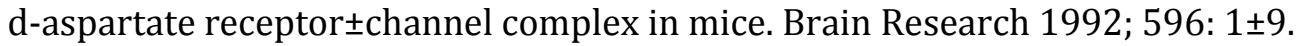


9. Finck AD, Ngai SH. Opiate receptor mediation of ketamine analgesia. Anesthesiology 1982; 56: $291 \pm 7$.

10. Tung A, Yaksh T. Analgesic effect of intrathecal ketamine in the rat. Regional Anesthesia 1981; 6: $91 \pm 4$.

11. Iida H, Dohi S, Tanahashi T, Watanabe Y, Takenaka M. Spinal conduction block by intrathecal ketamine in dogs. Anesthesia and Analgesia 1997; 85: 106 \pm 10 .

12. Frenkel C, Urban BW. Molecular actions of racemic ketamine on human CNS sodium channels. British Journal of Anaesthesia 1992; 69: 292 \pm 7.

13. Unlugenc $\mathrm{H}$, Ozalevli $\mathrm{M}$, Gunes $\mathrm{Y}$ et al. A double blind comparison of intrathecal $\mathrm{S}(+)$ ketamine combined with bupivacaine 0.5\% for caesarean delivery. Eur J Anaesthesiology.2006; 23 (12): 1018-24.

14. Kaliyani Govindan, Rajmani Krishnan, Marc P. Kaufman, et al. Intrathecal ketamine in surgeries for lower abdomen and lower extremities. Proc. West. Pharmacol. Soc 2001; 44: 197-199.

15. T. Tiogal, S. Demirbilek, A Koroglu, et al. Intrathecal ketamine with bupivacaine for prostate surgery in elderly patients. Eur Anaesthesiology. 2004; 21 (3): 193-7.

16. Dipasri Bhattacharya, Arnab Banerjee. Comparative study between intrathecal bupivacaine and intrathecal ketamine. Indian j Anaesth. 2004; 48 (2): 116-120.

17. Yang CY, Wong CS, Chang JY, et al. Intrathecal ketamine in patients with terminal cancer pain. Can J Anaesth. 1996; 43 (4): 379-83.

18. Marzieh BK, Javed G, Navid M et al. Evalution of the analgesic effect of ketamine ass an additive to intrathecal bupivacaine in patients undergoing caesarian section. Acta Anaesthesilogica taiwanica.2013; 155-160.

\section{AUTHORS:}

1. Amit Jain

2. Satyendra Uike

3. Nidhi Mishra

4. Sarvesh Jain

5. V. M. Agnihotri

\section{PARTICULARS OF CONTRIBUTORS:}

1. Assistant Professor, Department of Anaesthesiology, Bundelkhand Medical College, Sagar.

2. Assistant Professor, Department of Anaesthesiology, Bundelkhand Medical College, Sagar.

3. Assistant Professor, Department of Obstetrics and Gynaecology, Bundelkhand Medical College, Sagar.

4. Associate Professor, Department of Anaesthesiology, Bundelkhand Medical College, Sagar.
5. Professor, Department of Anaesthesiology, Chirayu Medical College, Bhopal.

\section{NAME ADDRESS EMAIL ID OF THE CORRESPONDING AUTHOR:}

Dr. Amit Jain,

C/o Arvind Jain, \#62, Dr. Shukta Marg,

Behind Bhagyoday,

Tirth Khurai Road,

Sagar, M. P.

Email: tosynapse@rediffmail.com

Date of Submission: 25/08/2014. Date of Peer Review: 26/08/2014. Date of Acceptance: 10/09/2014. Date of Publishing: 24/09/2014. 